\title{
Creating a digital model of regional relief using GIS technologies to evaluate degradation processes
}

\author{
Dilrabo Kadirova ${ }^{1, *}$, Matlyuba Usmanova $^{2}$, Munisa Saidova ${ }^{1}$, Gulnora Djalilova $^{2}$, and \\ Normamat Namozov ${ }^{1}$ \\ ${ }^{1}$ Tashkent State Agrarian University, University str., 2, Tashkent province, 100140 Uzbekistan \\ ${ }^{2}$ National University of Uzbekistan named after Mirzo Ulugbek, University str., 4, Tashkent, 100174 \\ Uzbekistan
}

\begin{abstract}
This paper presents the results of research on the creation of a digital model of relief by processing remote sensing data using geographic information systems to identify and assess areas at risk of degradation. According to the results of the study, the relief of the region is important in the occurrence and acceleration of degradation processes.
\end{abstract}

\section{Introduction}

It is well known that soil degradation is one of the global problems all over the world. As a result of various soil degradation processes, 6 million hectares of agricultural land around the world become unusable every year $[1,2]$. From an agricultural point of view, land degradation is determined by a decrease in the productive properties of soils, i.e., a decrease in biomass or productivity for humans and livestock. From the ecological point of view, land degradation means damage to the terrestrial ecosystem $[3,6,9]$. According to Liberti et al [12], the manifestation of degradation occurs as a result of the interaction of complex natural and anthropogenic factors.

Soil degradation can also be studied in a variety of ways, including direct field observations and remote sensing [4-6]. At present, it is impossible to imagine the study of soil cover, mapping of soils, its correction without remote data. Remote sensing is one of the most important and irreplaceable parts in land survey studies. Advances in modern space technology and imaging equipment make it possible to analyze, study, evaluate and map the state of different areas of the region [7].

The remote sensing method is more economical and efficient than traditional methods and is important in controlling large areas through a single image [7, 18]. Numerous scientific studies have been conducted on remote sensing data processing and identification of degraded lands using geographic information systems (GIS). Images obtained on the basis of remote sensing allow rapid and qualitative detection of degraded lands at different levels $[7,10]$. In addition, remote sensing data are effective in modeling soil leaching [11, $13,14]$.

\footnotetext{
* Corresponding author: d.qodirova@inbox.ru
} 
Processing of remote sensing data and obtaining detailed information on the use of GIS technologies and soil cover allows to model soil degradation processes [22]. The potential of this technology also increases in the development of integrated experimental models for predicting degradation processes [17]. Predicting the degradation process based on GIS technology allows not only to estimate soil loss, but also to predict the area of degradation distribution [19]. GIS technologies play an important role in the identification and mapping of lands at high risk of degradation, as well as in the development of the necessary measures to prevent degradation [21]. Studies conducted by the above scientists have proven that remote sensing of the Earth and GIS technology can be successfully used in accurate and high-quality mapping of land degradation processes [15, 16, 20, 23]. Studies have shown that the use of remote sensing data using GIS technology to monitor and map degraded soil cover has the potential to create high-quality electronic maps in Uzbekistan $[1-4,18]$.

Thus, there are problems specific to their conditions in the efficient use of desert pasture soils. Desert pasture soils have their own specific characteristics, in which the development of degradation processes leads to changes in the natural soil cover and deterioration of their properties. Therefore, the problems of restoring, protecting and preserving the fertility of degraded desert pasture soils are among the current issues.

\section{Materials and methods}

The research area is sandy desert soils in the desert pastures of Jizzakh province (surrounding areas of the Aydar Arnasay Lakes System) in Uzbekistan.

Field experiments, laboratory and in-camera methods were used during the studies. Also, as a result of topographic and geodetic works, the geographical coordinates of the location of soil sections were determined using a GPS device. During the research, Adobe Photoshop professional software was used to edit the rasterized images. The coordinates of the detected soil sections were processed on a computer using the program SKI-2.3. The remote data was processed using special GIS technology ArcGIS 10.6.1, SAS Planet, Global Mapper software. A special ENVI program was also used to classify the pixels.

An idea of the condition of the soil cover is provided by conventional field studies. However, maps structured in this way do not always provide accurate and up-to-date information. In addition, the heavy labor and high costs incurred for mapping do not allow for the constant dynamics of degradation processes. Due to the active introduction of Earth remote sensing methods based on the decoding of aerospace images to date, it allows to cover a certain area by monitoring, determining the forms of degradation processes, assessing the dynamics and obtaining objective information about the current state of soil cover.

The problem of modernization of soil cartography in Uzbekistan has long been posed to scientists. Experimental research in recent years has focused on the development of methods for using remote sensing and GIS technology data, as well as the substantiation of adaptive-landscape farming in soil mapping and the study of soil cover transformation. Based on the above, the development of computerized GIS technologies is moving from the stage of mastering the capabilities of software and hardware through the creation of various digital maps and databases to the stage of application of GIS technologies in production [11-16]. One of the most important tasks is to create custom-oriented maps based on existing and new data.

We know that one of the most important factors contributing to the development of degradation processes is relief. Relief has the property of distributing heat, moisture, organomineral and mineral substances as a soil-forming factor. This in turn leads to the formation of different soil types in different elements of the relief. Among other factors, 
relief causes a variety of soil cover. It is precisely the relief in areas with the same climatic conditions and soil-forming rocks that determines the structure of the soil cover and significantly affects the use of the land in agriculture.

The relief of the earth's surface is formed under the combined influence of endogenous and exogenous factors, the manifestation of degradation depends on the development of the lithological structure and paleogeographic conditions of the region.

A digital map is a digital model of a mathematical framework adopted for maps and thematic details in a particular direction that meets the requirements for content, accuracy, and reliability, corresponding to the nomenclature of selected projections and graphs [4-8, 12-15]. The digital map incorporates a discrete, targeted, focused digital record on topographic map sheets. A digital map consists of two parts that differ from each other in data entry, storage, processing, and similar features, namely the digital mapping framework and thematic content.

\section{Results and discussion}

The steps for creating digital soil maps included the following processes in this study:

\subsection{Preparation of map data}

Soil maps and related applications (soil survey statements, agrochemical maps and maps of eroded soils) may be in poor condition or some of this data may be lost altogether. For this reason, in order not to lose the available data, it is necessary to carefully analyze the maps, especially the reports of soil surveys. Soil maps are scanned and saved in JPEG format. Images created in this way are simply processed in a graphics editor, and in most cases in a GIMP editor. Editing tasks include preparing the soil maps for placement, as well as integrating them by stitching individual scanned sheets of the soil map, framing, and changing the brightness, contrast, and size of the image.

Remote sensing data - satellite imagery - can be obtained from any source that is openly accessible. Cadastral maps are obtained from an open source - public maps of the register. Spatial image data and cadastral maps are also processed in a graphical editor.

\subsection{Geographical linking}

The mapping is done using the ArcGIS 10.6.1 program, which stores spatial data according to the KML 2.2 standard. The binding process is completed by capturing the ground map image in the ArcGIS 10.6.1 program so that the images are aligned with each other in such a way that the elements on the ground map match the relief elements in the space image. It is practically impossible to achieve complete alignment of the two images, as the soil map is in many respects a scheme that in itself reflects only the relative position of the soil contours on the ground. In addition, soil maps can be severely damaged due to improper storage conditions. Even with modern geographic editor tools, it is not always possible to correct such errors.

\subsection{Making a list of classifiers}

Working with attribute data includes soil survey reports, conditional symbols, and detailed study of soil map legend. During the analysis, the soil map of the farm, relief features, general table data on granulometric composition, chemical, physical and morphological properties of the soil are studied. The soil contour data is compared with the soil contours 
on the map to identify errors and omissions associated with errors in mapping, as well as changes during storage (conditional characters, sequence numbers, and inaccurate view of soil contour codes). The soil contours on the map are divided into separate taxonomic units according to the soil classification.

Attribute data is grouped in the form of tables in the form of MS Excel and MS Access in such a way that all units in the classification list must be entered in full without duplication. This creates a list of attribute data that is ready to be added to the SAS Planet program.

\subsection{Vectorization of the soil map in the context of the SAS Planet program}

The vectorization process involves the separation of spatial data from polygons (farm contours and plots of land) and points (soil sections, soil samples) in the raster data layer of soil maps and satellite images by creating a vector layer. Using the SAS Planet program allows you to solve tasks such as vectorizing objects, as well as entering attribute information related to topology elements. Soil maps and raster images of satellite images are the data to be included in this program. Vectorization of soil maps is done in the standard xml - sign language extended KML 2.2 - spatial data representation standard. The KML 2.2 standard is largely based on modern GIS technologies. The SAS Planet program also includes functions to control the sharpness of the raster image layer, which in turn allows you to adjust the vectorization of ground maps based on more modern data from satellite images.

\subsection{Enter the attribute information using the list entered in the SAS Planet program}

The results of the work of the SAS Planet program are the space and attribute data presented in a file in KML format. This information can then be reviewed and edited in the XML Notepad text editor.

\subsection{Importing data into ArcGIS 10.6.1}

This is the final step in the preparation process. SAS Planet - a KML file created during vectoring using the "Export map to ArcGIS" function is saved as an imported file in ArcGIS.

Creating a digital mapping framework is the first step in creating any mapping work. During the research, LANDSAT-8 space images were used to create a digital mapping framework. Satellite images contain not only geographical coordinates (x, y), but also Zcoordinates (altitude signs). As mentioned above, the initial paper-based scanning was performed using a tablet scanner for each sheet (tablet) of the map. The conversion of raster images into graphic images in jpg (or bmp, tiff) format was done in Photoshop.

During the study, a special TIN (Triangulation Irregular Network) model was developed in ArcGIS to represent the topography of the site (Fig. 1). Using the tertiary TIN model of relief, the Interpolation method of 3D Analyst (Surface/Create TIN from Features) was used to assess the elevation of the area above sea level, slope and other factors that cause soil degradation processes. 


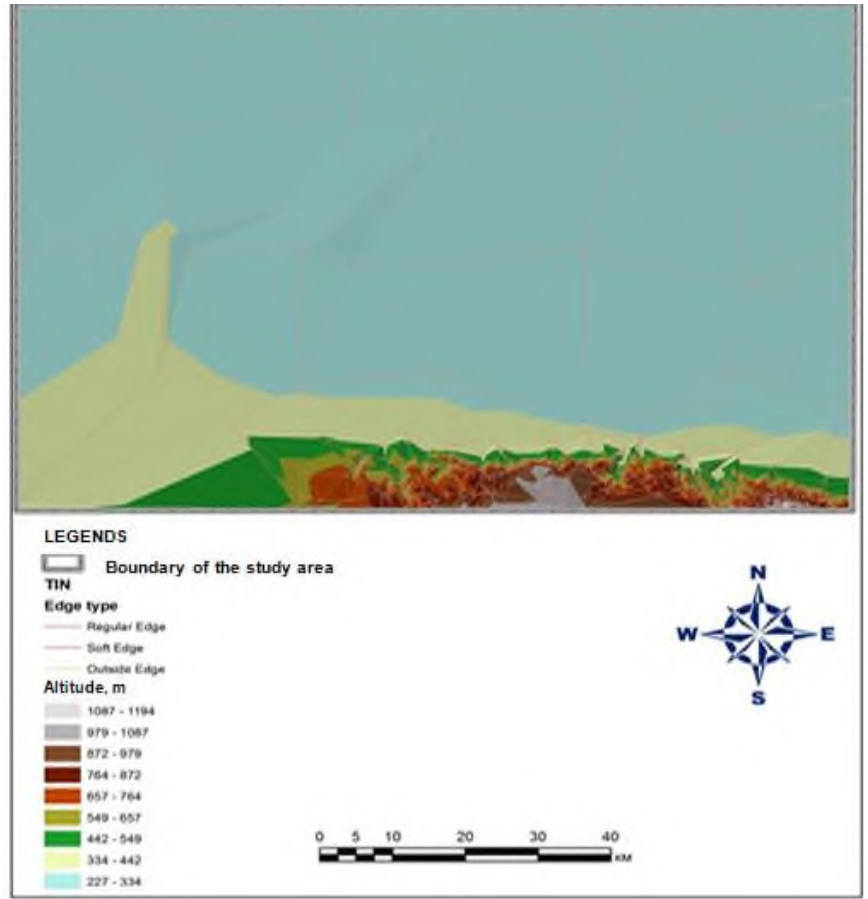

Fig. 1. Map of the TIN model of the relief of the study area.

Working in Global Mapper 17.0 allows you to create maps that reflect absolute characters in a horizontal view. During the study, a map of the topography of the area with a step of $50 \mathrm{~m}$ was created (Fig. 2).

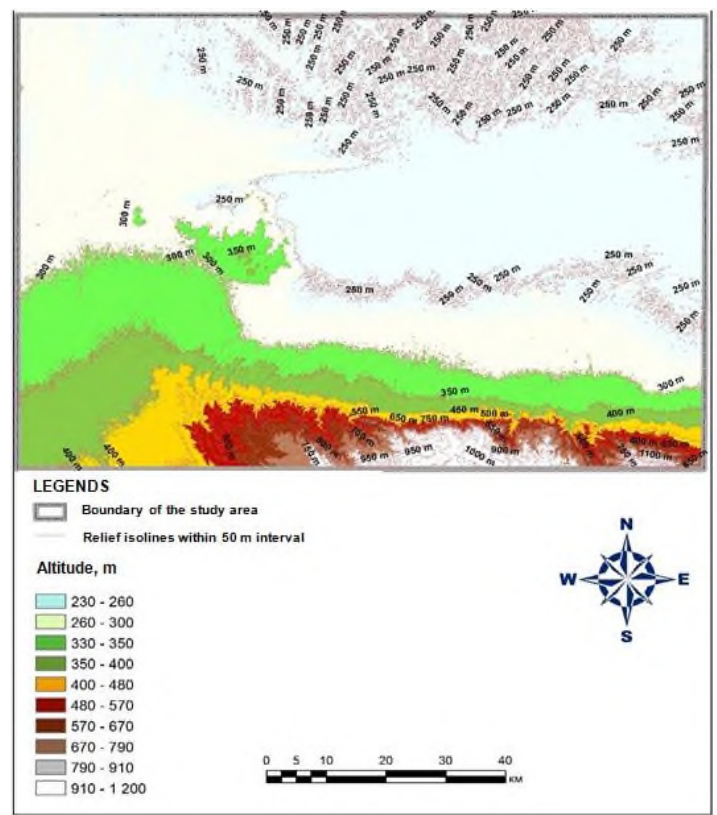

Fig. 2. Map of the TIN model of the relief of the study area. 
This map is an alternative to the topographic map, and the relief forms are inextricably linked to the history of the formation of deposits. A brief geological history of the area to be mapped, the stages of formation of deposits and their relationship to each other are covered. First of all, signs such as low, flat, elevation and plateau characterize the macro forms of relief, defining their breadth of distribution in the mapped area, as well as the absolute and relative elevations that are characteristic of them.

\section{Conclusion}

Development of a digital model of the terrain based on remote data processing using GIS technologies allows a detailed assessment of the degradation processes taking place in soils. This, in turn, has a number of advantages in the correct implementation of robust complex measures for the protection and degradation of land resources in different natural landscapes, as well as in the operative and accurate assessment of changes in soil fertility in different landforms. The description of the relief should take into account its role in production, meso- and micro-forms of relief in the use of land in agriculture and forestry.

GIS also provides accurate data on the condition of soils in the study area, soil cover, risk of land degradation in the analysis of the suitability of agricultural lands, the development of algorithms for assessing the degradation of land, soil protection measures, planting and placement of agricultural crops. allows the development of a number of environmentally and economically sound scenarios in the development of technologies to improve the results of evaluation work.

\section{References}

1. I. Aslanov, S. Khasanov, Y. Khudaybergenov, M. Groll, Ch. Opp, F. Li, E. Ramirez Del-Valle, In E3S Web of Conferences, 227, 02005 (2021)

2. A. Jumanov, S. Khasanov, A. Tabayev, G. Goziev, U. Uzbekov, E. Malikov, In IOP Conference Series: Earth and Environmental Science, 614(1), 012150 (2020)

3. R. Kulmatov, A. Taylakov, S. Khasanov, Environmental Science and Pollution Research, 28(10), 12245-12255 (2021)

4. Y. Peng, F. Li, N. Xu, R. Kulmatov, K. Gao, G. Wang, Y. Zhang, Y. Qiao, Y. Li, H. Yang, S. Hao, Q. Li, S. Khasanov, Chinese Journal of Eco-Agriculture, 29(2), 312-324 (2021)

5. R. A. Kulmatov, S. A. Adilov, S. Khasanov, In IOP Conference Series: Earth and Environmental Science, 614(1), 012149 (2020)

6. M. Lehoczky, Z. Abdurakhmonov, In E3S Web of Conferences, 227, 04001 (2021)

7. Z. Mamatkulov, J. Rashidov, G. Eshchanova, M. Berdiev, Z. Abdurakhmonov, In IOP Conference Series: Earth and Environmental Science, 614(1), 012086 (2020)

8. V. B. Asio, R. Jahn, F. Perez, I. Navarrete, S. Abit, Ann. Trop. Res., 31(2), 69-94 (2009)

9. A. El-Baroudy, Catena, 87(2), 201-208 (2011)

10. J. Gao, Y. Liu, Int. J. Remote Sens., 29(14), 4029-4043 (2008)

11. R. Gerken, M. Ilawi, Remote Sens. Environ., 90(4), 490-504 (2004)

12. M. Liberti, T. Simoniello, M. Carone, R. Coppola, M. Emilio, M. Macchiatto, Geomorphology, 106, 333-343 (2009)

13. D. Lu, M. Batistella, P. Mausel, E. Moran, Land Degrad. Dev., 18, 41-54 (2007) 
14. R. Mathieu, B. Cervelle, D. Remy, M. Pouget, Earth Surf. Proc. Land., 32, 13-31 (2007)

15. M. Abrams, International Journal of Remote Sensing, 21(5), 847-859 (2003)

16. I. Bayramin, G. Erpul, H. Erdogan, Turkish Journal of Agriculture and Forestry, 30, 81-100 (2006)

17. J. Dangermond, American Society for Testing and Materials, 11-17 (1991)

18. L. Gafurova, G. Djalilova, O. Ergasheva, D. Kadirova, Journal of Critical Reviews, 7(2), 283-287 (2020)

19. B. Alikhanov, S. Alikhanova, R. Oymatov, Z. Fayzullaev, A. Pulatov, IOP Conference Series: Materials Science and Engineering, 883(1), 012088 (2020)

20. M. Parlak, International Congress River Basin Management, 1, 844-859 (2007)

21. A. Vrieling, G. Sterk, N. Beaulieu, Journal of Soil and Water Conservation, 57, 158163 (2002)

22. A. Yuksel, A. Akay, R. Gundogan, M. Reis, M. Cetiner, Sensors, 8, 1222-1236 (2008)

23. G. Zhu, D. Blumberg, Remote Sensing Environment, 80, 233-240 (2001) 